\title{
Treatment of type 2 diabetes mellitus and risk of pancreatic cancer
}

\author{
Edyta Olakowska ${ }^{\circledR 1}$, Marek Olakowski ${ }^{\circledR 2}$ \\ ${ }^{1}$ Department of Physiology, Medical University of Silesia, Katowice, Poland \\ ${ }^{2}$ Department of Gastrointestinal Surgery, Medical University of Silesia, Katowice, Poland
}

\begin{abstract}
Pancreatic ductal adenocarcinoma (PDAC) is the most common cancer of the exocrine part of the pancreas, with poor prognosis. Up to $85 \%$ of PDAC patients are diagnosed with diabetes or hyperglycaemia at the time of cancer diagnosis. It indicates that impaired glucose homeostasis is a common event in PDAC. However, the mechanism of association between PDAC and diabetes is very complex and still not fully understood. The most important factor in the development of PDAC based on diabetes, is the long-term persistence of high intra-pancreatic insulin concentrations. A lowering of blood glucose levels is essential in type 2 diabetes mellitus management for the prevention and delayed progression of chronic complications. Currently, various classes of antidiabetic drugs are used in therapy. The influence of insulin treatment on the risk of PDAC is assessed as unclear. A recent analysis showed that this risk is higher in patients with new-onset diabetes. Insulin analogues were reported to be associated with PDAC, but recent trials did not confirm a significantly higher cancer risk. Metformin, recommended as the first-choice therapy in type 2 diabetes, possesses anti-cancer activity and can prolong the survival of PDAC patients. In can be used in monotherapy or with other antidiabetic drugs, such as SGLT-2 inhibitors, incretins, sulphonylureas, or thiazolidinediones. SGLT-2 inhibitors may be protective in PDAC by inhibiting tumour growth. Incretin-based therapy appears to have a beneficial effect in PDAC patients even after long-term therapy. Sulphonylureas and alpha-guanidine inhibitors are associated with a significantly lower risk of pancreatic cancer. But only one study reported an association between therapy with pioglitazone and an increased risk of PDAC.

It is possible that specific types of antidiabetic drugs may have different impacts on pancreatic cancer development. Moreover, the intriguing question of whether diabetes can facilitate PDAC development remains unanswered. This review presents the results of recent studies on the effect of anti-diabetic treatment on pancreatic cancer development and potential mechanisms associated with the activity of these drugs. (Endokrynol Pol 2021; 72 (4): 395-401)
\end{abstract}

Key words: pancreatic cancer; type 2 diabetes mellitus; anti-diabetic medication; pancreatic cancer risk

\section{Introduction}

Pancreatic ductal adenocarcinoma (PDAC) is the most common cancer of the exocrine part of the pancreas, with poor prognosis, accounting for more than $90 \%$ of cases [1].

Pancreatic ductal adenocarcinoma is the 11th most common human cancer worldwide and the 7 th most common cancer in western countries [2].

In Poland, 3486 cases of PDAC were reported in 2016, representing approximately $2 \%$ of all cancers diagnosed in our country [3].

Pancreatic ductal adenocarcinoma belongs to a small group of cancers with an increasing incidence rate (1-2\% per year for more than a decade). Additionally, it has one of the lowest overall 5-year survival rates, currently at $9 \%$ [4].

There is an alarming prognosis that by 2030 PDAC will be the second cancer for mortality in the US [5].
The main risk factors for PDAC are tobacco smoking, alcohol consumption, obesity, and type 2 diabetes; others are also suspected, such as dietary factors and allergy [6].

\section{Type 2 diabetes mellitus}

Type 2 diabetes mellitus (T2DM) is the third modifiable risk factor for PDAC after smoking and obesity [7].

T2DM is defined as a group of metabolic diseases characterized by hyperglycaemia due to a defect of insulin secretion and/or its action. The main cause of T2DM is a progressive impairment of insulin secretion by $\beta$ cells and insulin resistance in various tissues, e.g. skeletal muscles, adipocytes, and liver. Dysfunction of $\beta$ cells is associated with the complex interactions between environmental and molecular factors, such as hyperglycaemia, hyperlipidaemia, and chronic inflammation, which can induce a loss of pancreatic islet 
integrity and apoptosis. Moreover, the disturbances in the synthesis and secretion of insulin and its precursors and a reduced expression of glucose transporters can contribute to diabetes foundation [8].

Chronic hyperglycaemia leads to the development of micro- and macrovascular complications and is associated with a failure of various organs, such as eyes, kidneys, nerves, blood vessels, and heart. Diagnostic criteria of diabetes include the following: symptoms of hyperglycaemia and random blood glucose level $\geq 200 \mathrm{mg} / \mathrm{dL}(\geq 11.1 \mathrm{mmol} / \mathrm{L})$, fasting blood glucose level (FGL) $\geq 126 \mathrm{mg} / \mathrm{dL}$ ( $\geq 7.0 \mathrm{mmol} / \mathrm{L})$ on two occasions, blood glucose at 120 minutes of OGTT $\geq 200 \mathrm{mg} / \mathrm{dL}(\geq 11.1 \mathrm{mmol} / \mathrm{L})$, and glycated haemoglobin $\left(\mathrm{HbA}_{1 \mathrm{c}}\right)$ level $\geq 6.5 \%[9,10]$.

The incidence of diabetes in PDAC is higher than the occurrence of diabetes in a group of other cancers. Moreover, the main risk factors for T2DM such as age, obesity, and a family history of diabetes are also risk factors for PDAC [11].

Up to $85 \%$ of PDAC patients are diagnosed with diabetes or hyperglycaemia at the time of diagnosis, indicating that impaired glucose homeostasis is a common event in this cancer. In a population-based cohort study of US PDAC patients $(\mathrm{n}=219)$, it was reported that $42 \%$ of them met the American Diabetes Association criteria for diabetes. Among them, 52\% had new-onset diabetes (NOD), 13\% had advanced pre-diabetes - as indicated by FGL $\geq 120 \mathrm{mg} / \mathrm{dL}, 21 \%$ had an abnormal FGL, and only $9 \%$ had a normal FGL at the time of cancer diagnosis [12].

A prospective study of 512,000 adult people and a meta-analysis of 22 cohort studies found that in Chinese and non-Chinese populations, not only diabetes but also hyperglycaemia in both people with and without diabetes were associated with an increased risk of PDAC. Among individuals without diabetes, for every $1 \mathrm{mmol} / \mathrm{L}$ higher blood glucose level, there was a $15 \%$ increase in PDAC risk [13].

Epidemiological studies revealed that long-standing type 2 diabetes mellitus (LSDM) is associated with a 1.5to 2.0-fold increase in the risk of PDAC [7].

Patients with newly diagnosed diabetes have as much as a 5-8-fold increased risk of being diagnosed with PDAC within 1-3 years of onset [14].

Because LSDM is a risk factor for PDAC and, conversely, PDAC in many cases is a putative cause of new onset diabetes (NOD), diabetes and PDAC are considered to exhibit "dual causality". But the mechanisms of these associations are unclear, as are the diagnostic criteria to distinguish LSDM from diabetes that occurrs as an early event of PDAC [11].

Among NOD patients over the age of 50 years, PDAC is diagnosed in approximately $1 \%$ within 3 years. The
ENDPAC (Enriching New-Onset Diabetes for Pancreatic Cancer) model was developed to determine the risk of $P C$ in patients with NOD. It includes 3 factors identified in the cohort as most strongly associated with PDAC: (1) change in body weight, (2) change in blood glucose levels, and (3) age at onset of diabetes. The ENDPAC model attributes patients with NOD to 3 groups, based on 3-year pancreatic cancer risk: low $(<0.1 \%)$, intermediate (about $0.5 \%$ ), and very high (about $4 \%$ ). Based on glycaemic status, the ENDPAC model can help identify $75 \%$ of PDAC patients with NOD 6 months before the cancer diagnosis [15].

The mechanism of association between PDAC and diabetes is very complex and still not fully understood. Insulin receptors share significant homology and similar signalling pathways with insulin growth factor 1 (IGF-1) receptor; thus, IGF-1 can bind to insulin receptor and then stimulate cell proliferation [16].

Insulin has mitogenic activity and can stimulate cell growth without malignant transformation. But the hormone can also stimulate the growth of transformed cells and thus increase the incidence of tumour development. It has been suggested that a direct effect of insulin especially in hyperinsulinaemia could partly explain the increased incidence of cancer [17].

In the development of PDAC on the basis of diabetes, as in pathological obesity, the most important factor is the long-term persistence of high intra-pancreatic insulin concentrations. Augmented intra-pancreatic insulin is a consequence of continuous stimuli flowing to the $\beta$ cells resulting from the peripheral insulin resistance. The hormone released by $\beta$ cells arrives with the blood via the intra-pancreatic portal circulation to the follicular and ductal cells adjacent to the islets. Insulin molecules released in excess activate insulin receptors present on the surface of papillary cells and any transformed cells that may arise in this region, promoting their survival and proliferation. Thus, particularly intra-pancreatic hyperinsulinaemia, resulting from obesity and insulin resistance in pre-diabetes or early diabetes, is likely to contribute to the observed increased risk of PDAC [11].

Moreover, the increased availability of glucose or lipids observed in diabetes and obesity is responsible for the increased synthesis of highly reactive carbonyl compounds, a condition referred to as 'carbonyl stress'. These compounds, also known as glycotoxins and lipotoxins, rapidly react and damage various molecules in cells, forming end products known as AGEs (advanced glycation end-products). AGEs were shown to significantly accelerate tumour growth in an experimental pancreatic cancer model, while inhibition of AGEs prevented the cancer-promoting effect of diabetes. These results suggest that carbonyl stress is involved in cancer 
development and growth and potentially links diabetes and PDAC, providing a target for drugs [18].

Additionally, evidence of an association between hyperglycaemia and genomic instability has recently been found in pancreatic cancer. High glucose level can increase post-translational O-GlcNAcylation, leading to nucleotide imbalance and genomic instability supporting KRAS mutations [19].

Another possible mechanism that can influence the development of PDAC is associated with cancer stem cells (CSC). They are supposed to account for tumour initiation, progression, recurrence, and therapy resistance due to their unique ability to self-renew and give rise to differentiated cells, as well as their profound survival strategies. A study on pancreatic cancer cell lines (Panc 1) showed that hyperglycaemia promotes the acquisition of mesenchymal and CSC properties in PDAC by activating TGF- $\beta$ signalling and might explain how T2DM facilitates pancreatic tumourigenesis [20].

\section{Antidiabetic drugs}

Currently, various classes of antidiabetic drugs are used in diabetes management. The most often applied drugs include insulin and insulin analogues, biguanides, sodium-glucose co-transporter-2 (SGLT-2) inhibitors, glucagon-like peptide-1 (GLP-1) agonists, dipeptidyl peptidase-4 (DPP-4) inhibitors, sulphonylureas, thiazolidinediones, and alpha glucosidase inhibitors.

\section{Insulin and insulin analogues}

Insulin therapy is the oldest form of treatment for diabetes administered both in type- 1 and type- 2 of the disease. Besides lowering the glucose level in blood, insulin can act as a growth factor and cause a proliferation and transformation of various cells [17].

Insulin analogues are synthesized by modification of amino acids in the insulin chain, which allows the creation of rapid (e.g. lispro) and long-acting (e.g. glargine) drugs.

A comparison of insulin with its analogues found that the analogues had a higher IGF-1 receptor affinity and also a lower differentiation rate than the human insulins [21].

In physiological conditions insulin is released from the pancreas into the portal vein, and it reaches hepatocytes, where inhibits gluconeogenesis and glycolysis. Insulin analogues administered subcutaneously are bound to serum proteins and then released in the peripheral tissue/adipose tissue and muscles [22].

Earlier studies proved that diabetic patients treated with insulin had a significantly higher risk of pancreatic cancer than patients treated with other hypoglycaemic agents [23].
In newer studies the effect of insulin on the risk of PDAC in patients with T2DM was assessed as unclear; a short period of insulin use ( $<5$ years) significantly increased PDAC risk, while a longer period ( $>15$ years) did not [24].

Moreover, there is no evidence that the insulin analogues have a higher mitogenic potential than a human insulin. The long-term, randomized control ORIGIN (Outcome Reduction with an Initial Glargine Intervention) trial did not demonstrate an increased risk of any cancer in patients using glargine [25].

A recent analysis showed that the risk of PDAC associated with insulin therapy is dependent not so much on the type of the drug but more on the diabetes subtype. This risk is higher in patients with the NOD diabetes subtype than in the LSDM subgroup. An explanation for this phenomenon is related to the fact that in the NOD, insulin treatment was started earlier due to a faster or more aggressive disease progression, consequently leading to $\beta$-cell dysfunction, impaired proinsulin processing, and the development of insulin resistance [26].

\section{Biguanides}

Biguanides are derivatives of guanidine. Nowadays, a representative of, and the only available drug from, this group is metformin. For many years metformin has been the gold standard in the treatment of type 2 diabetes. According to recommendations from the most important diabetes associations, this is the first-choice drug for use as monotherapy in patients with newly diagnosed T2DM $[8,27]$.

Metformin acts as a glucose-lowering agent through the inhibition of hepatic glucose synthesis and an augmentation of peripheral glucose uptake in the skeletal muscles and fatty tissue. Additionally, it is safe and cost-effective [28-30].

Antidiabetic effects of metformin result mainly from the influence on a pathway of enzyme AMP-activated protein kinase (AMPK) that is a regulator of the glucose, lipids, and protein metabolism in the cell. It was proven that phosphorylation of AMPK is required for metformin's inhibitory effect on glucose production by hepatocytes and its uptake by skeletal muscles [31].

Moreover, metformin can suppress inflammation by changes in the cytokine level in blood and inhibition of the differentiation of monocytes into macrophages. The latest observations show that the drug can modify a microbiome in the intestine and thus enhance glucose intestinal absorption and utilization in enterocytes, which can limit the access of glucose to the blood [32].

Experimental studies have described the mechanism by which metformin may reduce the risk of PDAC and 
improve the survival of patients with coexisting glucose tolerance impairment. Primarily, it decreases insulin/IGF signalling, disrupting mitochondrial respiration and inhibiting the mammalian target of rapamycin (mTOR) pathway. Other potential anti-cancer activities of metformin include its ability to affect transcription factors of specific proteins and related genes, alter microRNAs, reduce cancer stem cell proliferation, and decrease DNA damage, as well as inhibit inflammatory responses [33].

Recently, many papers have been published examining the risk of PDAC in patients with T2DM treated with metformin. While much evidence has been presented to suggest an anti-cancer effect of metformin, the results of clinical work often provide conflicting information.

A Polish clinical trial [34] as well as a recent large meta-analysis [35] that included 67 articles $(10,695,875$ people with diabetes, including 145,108 cases of cancer) showed that metformin may be an independent protective factor against cancers, including pancreatic cancer, in patients with T2DM.

Other clinical trials have shown that metformin can prolong the survival of PDAC patients who were treated with this drug prior to cancer diagnosis [36].

However, in a cohort study involving 66,627 patients (including 29,974 using metformin), there was no statistical difference compared to the control group $(n=36,653)$ in the incidence of PDAC in diabetic patients [37].

Another meta-analysis showed a beneficial role of metformin, although data from randomized controlled trials did not support these results [38].

A possible explanation for the differences in the results, particularly of cohort studies conducted by different teams on the relationship between metformin and PDAC survival, may be the high heterogeneity of the analysed data [39].

It is important to recognize that newer and better designed studies have weakened the previously strong evidence for reduced PDAC risk among people with type 2 diabetes using metformin [40].

Nowadays, there are also increasing attempts to use metformin not only in cancer prevention and treatment but also to decrease the mortality among people with diabetes and concurrent COVID-19 disease [41, 42].

If metformin monotherapy is not tolerated or contraindicated, other antidiabetic drugs should be applied [8].

\section{Sodium-glucose co-transporters-2 (SGLT-2) inhibitors}

Sodium-glucose cotransporter-2 (SGLT2) proteins are expressed in the proximal tubule of the kidneys, and they are responsible for approximately $90 \%$ of filtered glucose reabsorption. SGLT-2 inhibitors (e.g. dapagliflozin, empagliflozin) act through a mechanism of reducing renal tubular glucose reabsorption and producing a reduction in the blood glucose level without stimulating insulin release. Other benefits may include favourable effects on blood pressure and weight, so SGLT2 inhibitors may be a useful option in obese and hypertensive patients [43].

The expression of SGLT2 can be up-regulated in patients with T2DM, causing an inadequate response that deteriorates hyperglycaemia [44].

They can be combined with metformin [8] or applied as a second-line treatment when other antidiabetic drugs did not provide adequate glycaemia [22].

Tang et al., in a systematic review and meta-analysis of 35 randomized trials (including 44912 patients), did not find an association between SGLT2 inhibitors and increased risk of PDAC in patients with T2DM. Moreover, they might be protective in PDAC by inhibiting tumourigenesis and could be a potential target in therapy [45].

\section{Incretins}

GLP-1 (glucagon-like peptide-1) and DPP-4 (dipeptyl-peptidase-4) are secreted from enteroendocrine cells of the intestine after eating and then stimulate the pancreas to release insulin together with hyperglycaemia (the incretin effect). In physiological conditions GLP-1 can also suppress appetite and the synthesis of glucose in the liver. GLP-1 can be degraded by enzyme DPP-4. Agonists of GLP-1 (e.g. dulaglutide, liraglutide) and inhibitors of DPP-4 (e.g. sitagliptin, linagliptin) are insulinotropic factors, and they can stimulate the secretion of insulin induced by glucose and inhibit the release of glucagon [22].

The main advantage of these drugs is the lack of increased risk of hypoglycaemic episodes, and without weight gain [46].

Currently, incretins can be applied as first-line treatment if there is an intolerance or contraindication to metformin therapy [47].

A large meta-analysis based on six prospective randomized controlled trials (EXMAINE, ELIXA, LEADER, SAVOR-TIMI53, SUS-TAIN-6, LEADER, and TECOS) with 55,248 patients with T2DM using incretin-based drugs revealed no significant effects on the risk of cardiovascular and pancreatic diseases (acute pancreatitis and pancreatic cancer) [48].

Similarly, a study published in 2019 based on a large database of randomized, placebo-controlled, prospective cardiovascular outcome studies with GLP-1 receptor agonists and DPP-4 inhibitors found no association 
between this group of drugs and the risk of pancreatic and other cancers after long-term therapy [4According to a recent meta-analysis, the association between the use of DPP-4 inhibitors and the risk of PDAC in patients with T2DM was also not confirmed $[50,51]$.

\section{Sulphonylureas}

Sulfonylureas (Sus) (e.g. glibenclamide, glimepiride) increase insulin secretion from pancreatic $\beta$ cells in a non-glucose-dependent manner. They bind to the receptor SUR (sulphonylurea receptor) subunit of the ATP-sensitive potassium channel (KATP) and then can inhibit the channel. Such inhibition causes changes in depolarization of the beta-cell membrane, and stimulate influx of $\mathrm{Ca}^{2+}$ and release of the hormone from granules [52].

Sulphonylureas also have various extrapancreatic effects such as reducing secretion of glucagon and insulin clearance rate in the liver and enhancing peripheral tissue sensitivity to insulin. The main side effect of Sus is increased risk of hypoglycaemia due to their glucose-independent action as insulin secretagogues [53].

A few prospective and randomized controlled studies (e.g. the ADVANCE trial) have shown that use of SUs did not increase the all-cancer risk in T2DM patients compared to T2DM patients not using Sus [54-56].

Ye et al. in a population-based cohort study estimated the pancreatic cancer risk in 653 new-onset T2DM patients using Sus and revealed that sulphonylureas monotherapy was associated with significantly lower risk of pancreatic cancer [57].

Dankner et al., in a review of the scientific literature concerning an association between the use of various antidiabetic medications and risk of any cancer, confirmed that Sus had no influence on the risk of pancreatic cancer in patients with T2DM [40].

Meglitinides (e.g., repaglinide and nateglinide) are non-sulfonylurea secretagogues that share the same mechanism as that of sulfonylureas, but the binding to the receptor is weaker than with SUs. Meglitinides are short-acting anti-diabetic agents and play valuable roles in lowering postprandial hyperglycaemia and reducing hypoglycaemia. They can be applied in patients with irregular meal schedules or those who develop late postprandial hypoglycaemia while using SUs [58].

Li et al., in a case-control study involving 973 patients with PDAC (including 259 diabetic patients) and 863 controls (including 109 diabetic patients), revealed that insulin secretagogues (SUs and meglitinides) used as a monotherapy showed the highest risk of PDAC. The risk of PDAC was increased in short-term users but not in long-term users of insulin secretagogues compared with never users [59].

\section{Thiazolidinediones}

These are a group of anti-diabetic drugs that bind to a specific receptor - PPAR $\gamma$ (peroxisome-proliferator activated receptor gamma) - and can regulate glucose homeostasis in blood. Beneficial effects of PPAR $\gamma$ agonists include lowering of postprandial and fasting glucose level, an improvement of $\beta$-cell function and lipid profile in blood, as well as lowering of blood pressure and microalbuminuria. Additionally, they are safe and well tolerated, but a major drawback is non-intentional body weight gain.

Thiazolidinediones can also improve $\beta$-cell function and insulin resistance in peripheral tissues and the liver $[60,61]$.

Pioglitazone is the only drug from this group used globally, because others are associated with a risk of hepatotoxicity and cardiovascular disease [62].

Only in one study was treatment with pioglitazone associated with an increased risk of pancreatic cancer [63].

\section{Alpha-glucosidase inhibitors}

Alpha-glucosidase inhibitors (AGIs) can delay the absorption of glucose and other carbohydrates in the small intestine by competitive and reversible inhibition of the enzyme alpha-glucosidase. Acarbose is a representative drug of AGIs, but also miglitol and vioglibose are used for glycaemic control. AGIs are safe and effective both in geriatric and younger patients, but the limitation for wider use of these drugs is poor tolerability, with side effects from the GI tract (diarrhoea, abdominal pain) [64].

A meta-analysis of 1399 studies showed that this group of drugs is associated with a reduced risk of PDAC in diabetic patients, probably by lowering the insulin level in blood [65].

\section{Conclusions}

A strategy for clinical management to improve the outcome of diabetic patients with PDAC has not been established so far. Antidiabetic therapy should be individualized considering the effectiveness of lowering blood glucose levels, risk of hypoglycaemia, cardiovascular and renal risk, influence on body weight, and possible side effects. Moreover, the intriguing question of whether diabetes can facilitate PDAC development remains unanswered. Currently, targeted diagnostic and therapeutic strategies are needed to improve the poor survival rates for diabetic patients with PDAC. 


\section{References}

1. Paternoster S, Falasca M. The intricate relationship between diabetes, obesity and pancreatic cancer. Biochim Biophys Acta Rev Cancer. 2020; 1873(1): 188326, doi: 10.1016/j.bbcan.2019.188326, indexed in Pubmed: 31707038.

2. Bray F, Ferlay J, Soerjomataram I, et al. Global cancer statistics 2018: GLOBOCAN estimates of incidence and mortality worldwide for 36 cancers in 185 countries. CA Cancer J Clin. 2018; 68(6): 394-424, doi: 10.3322/caac.21492, indexed in Pubmed: 30207593.

3. Wojciechowska U, Czaderny K, Ciuba A, Olasek P, Didkowska J. Cancer in Poland in 2016. Krajowy Rejestr Nowotworów, Warszawa 2018.

4. Siegel RL, Miller KD, Fuchs HE, et al. Cancer Statistics, 2021. CA Cancer J Clin. 2021; 71(1): 7-33, doi: 10.3322/caac.21654, indexed in Pubmed: 33433946.

5. Rahib L, Smith BD, Aizenberg R, et al. Projecting cancer incidence and deaths to 2030: the unexpected burden of thyroid, liver, and pancreas cancers in the United States. Cancer Res. 2014; 74(11): 2913-2921, doi: 10.1158/0008-5472.CAN-14-0155, indexed in Pubmed: 24840647.

6. Lu Ye, Gentiluomo M, Lorenzo-Bermejo J, et al. Mendelian randomisation study of the effects of known and putative risk factors on pancreatic cancer. J Med Genet. 2020; 57(12): 820-828, doi: 10.1136/jmedgenet-2019-106200, indexed in Pubmed: 32066631.

7. Li D. Diabetes and pancreatic cancer. Mol Carcinog. 2012; 51(1): 64-74, doi: 10.1002/mc.20771, indexed in Pubmed: 22162232.

8. Galicia-Garcia U, Benito-Vicente A, Jebari S, et al. Pathophysiology of Type 2 Diabetes Mellitus. Int J Mol Sci. 2020; 21(17), doi: 10.3390/ijms21176275, indexed in Pubmed: 32872570.

9. DeFronzo RA, Ferrannini E, Groop L, et al. Type 2 diabetes mellitus. Nat Rev Dis Primers. 2015; 1: 15019, doi: 10.1038/nrdp.2015.19, indexed in Pubmed: 27189025.

10. Araszkiewicz A, Bandurska-Stankiewicz E, Budzyński A, et al. 2019 Guidelines on the management of diabetic patients. A position of Diabetes Poland. Clin Diabetol. 2019; 8(1): 1-95, doi: 10.5603/dk.2019.0001.

11. Andersen DK, Korc M, Petersen GM, et al. Diabetes, Pancreatogenic Diabetes, and Pancreatic Cancer. Diabetes. 2017; 66(5): 1103-1110, doi: 10.2337/db16-1477, indexed in Pubmed: 28507210.

12. Singhi AD, Koay EJ, Chari ST, et al. Early Detection of Pancreatic Cancer: Opportunities and Challenges. Gastroenterology. 2019; 156(7): 2024-2040, doi: 10.1053/j.gastro.2019.01.259, indexed in Pubmed: 30721664.

13. Pang Y, Kartsonaki C, Guo Yu, et al. Diabetes, plasma glucose and incidence of pancreatic cancer: A prospective study of 0.5 million Chinese adults and a meta-analysis of 22 cohort studies. Int J Cancer. 2017; 140(8): 1781-1788, doi: 10.1002/ijc.30599, indexed in Pubmed: 28063165.

14. Sah RP, Nagpal SJ, Mukhopadhyay D, et al. New insights into pancreatic cancer-induced paraneoplastic diabetes. Nat Rev Gastroenterol Hepatol. 2013; 10(7): 423-433, doi: 10.1038/nrgastro.2013.49, indexed in Pubmed: 23528347.

15. Sharma A, Kandlakunta H, Nagpal SJ, et al. Model to Determine Risk of Pancreatic Cancer in Patients With New-Onset Diabetes. Gastroenterology. 2018; 155(3): 730-739.e3, doi: 10.1053/j.gastro.2018.05.023, indexed in Pubmed: 29775599.

16. Shafiei-Irannejad V, Samadi N, Salehi R, et al. New insights into antidiabetic drugs: Possible applications in cancer treatment. Chem Biol Drug Des. 2017; 90(6): 1056-1066, doi: 10.1111/cbdd.13013, indexed in Pubmed: 28456998.

17. Pollak M. The insulin and insulin-like growth factor receptor family in neoplasia: an update. Nat Rev Cancer. 2012; 12(3): 159-169, doi: 10.1038/nrc3215, indexed in Pubmed: 22337149.

18. Menini S, Iacobini C, Vitale M, et al. Diabetes and Pancreatic CancerA Dangerous Liaison Relying on Carbonyl Stress. Cancers (Basel). 2021; 13(2), doi: 10.3390/cancers13020313, indexed in Pubmed: 33467038.

19. Hu CM, Tien SC, Hsieh PK, et al. High Glucose Triggers Nucleotide Imbalance through O-GlcNAcylation of Key Enzymes and Induces KRAS Mutation in Pancreatic Cells. Cell Metab. 2019; 29(6): 1334-1349. e10, doi: 10.1016/j.cmet.2019.02.005, indexed in Pubmed: 30853214.

20. Rahn S, Zimmermann V, Viol F, et al. Diabetes as risk factor for pancreatic cancer: Hyperglycemia promotes epithelial-mesenchymal-transition and stem cell properties in pancreatic ductal epithelial cells. Cancer Lett. 2018; 415: 129-150, doi: 10.1016/j.canlet.2017.12.004, indexed in Pubmed: 29222037.

21. Mannucci E. Insulin therapy and cancer in type 2 diabetes. ISRN Endocrinol. 2012; 2012: 240634, doi: 10.5402/2012/240634, indexed in Pubmed: 23209929.

22. Tokajuk A, Krzyżanowska-Grycel E, Tokajuk A, et al. Antidiabetic drugs and risk of cancer. Pharmacol Rep. 2015; 67(6): 1240-1250, doi: 10.1016/j. pharep.2015.05.005, indexed in Pubmed: 26481548.

23. Li D, Yeung SCJ, Hassan MM, et al. Antidiabetic therapies affect risk of pancreatic cancer. Gastroenterology. 2009; 137(2): 482-488, doi: 10.1053/j. gastro.2009.04.013, indexed in Pubmed: 19375425.

24. Bosetti C, Rosato V, Li D, et al. Diabetes, antidiabetic medications, and pancreatic cancer risk: an analysis from the International Pancreatic Cancer Case-Control Consortium. Ann Oncol. 2014; 25(10): 2065-2072, doi: 10.1093/annonc/mdu276, indexed in Pubmed: 25057164.
25. Gerstein HC, Bosch J, Dagenais GR, et al. ORIGIN Trial Investigators. Basal insulin and cardiovascular and other outcomes in dysglycemia. N Engl J Med. 2012; 367(4): 319-328, doi: 10.1056/NEJMoa1203858, indexed in Pubmed: 22686416.

26. Molina-Montes E, Coscia C, Gómez-Rubio P, et al. PanGenEU Study Investigators. Deciphering the complex interplay between pancreatic cancer, diabetes mellitus subtypes and obesity/BMI through causal inference and mediation analyses. Gut. 2021; 70(2): 319-329, doi: 10.1136/gutjnl-2019-319990, indexed in Pubmed: 32409590.

27. Wróbel MP, Marek B, Kajdaniuk D, et al. Metformin - a new old drug. Endokrynol Pol. 2017; 68(4): 482-496, doi: 10.5603/EP.2017.0050, indexed in Pubmed: 28819951.

28. Zhou J, Massey S, Story D, et al. Metformin: An Old Drug with New Applications. Int J Mol Sci. 2018; 19(10), doi: 10.3390/ijms19102863, indexed in Pubmed: 30241400.

29. Kułaczkowska ZM, Wróbel M, Rokicka D, et al. Metformin in patients with type 2 diabetes mellitus and heart failure: a review. Endokrynol Pol. 2021; 72(2): 163-170, doi: 10.5603/EP.a2021.0033, indexed in Pubmed: 33970481.

30. Hotta N. A new perspective on the biguanide, metformin therapy in type 2 diabetes and lactic acidosis. J Diabetes Investig. 2019; 10(4): 906-908, doi: 10.1111/jdi.13090, indexed in Pubmed: 31152685.

31. Duca FA, Côté CD, Rasmussen BA, et al. Metformin activates a duodenal Ampk-dependent pathway to lower hepatic glucose production in rats. Nat Med. 2015; 21(5): 506-511, doi: 10.1038/nm.3787, indexed in Pubmed: 25849133

32. Rena G, Hardie DG, Pearson ER. The mechanisms of action of metformin Diabetologia. 2017; 60(9): 1577-1585, doi: 10.1007/s00125-017-4342-z, indexed in Pubmed: 28776086.

33. Gong J, Robbins LA, Lugea A, et al. Diabetes, pancreatic cancer, and metformin therapy. Front Physiol. 2014; 5: 426, doi: 10.3389/fphys.2014.00426, indexed in Pubmed: 25426078.

34. Muszyńska-Ogłaza A, Zarzycka-Lindner G, Olejniczak H, et al Use of metformin is associated with lower incidence of cancer in patients with type 2 diabetes. Endokrynol Pol. 2017; 68(6): 652-658, doi: 10.5603/EP.a2017.0054, indexed in Pubmed: 29022647.

35. Zhang K, Bai P, Dai H, et al. Metformin and risk of cancer among patients with type 2 diabetes mellitus: A systematic review and meta-analysis. Prim Care Diabetes. 2021; 15(1): 52-58, doi: 10.1016/j.pcd.2020.06.001, indexed in Pubmed: 32605879.

36. Terasaki F, Sugiura T, Okamura Y, et al. Oncological benefit of metformin in patients with pancreatic ductal adenocarcinoma and comorbid diabetes mellitus. Langenbecks Arch Surg. 2020; 405(3): 313-324, doi: 10.1007/s00423-020-01874-3, indexed in Pubmed: 32367394.

37. Oh TK, Song IA. Metformin Use and the Risk of Cancer in Patients with Diabetes: A Nationwide Sample Cohort Study. Cancer Prev Res (Phila). 2020; 13(2): 195-202, doi: 10.1158/1940-6207.CAPR-19-0427, indexed in Pubmed: 31699707.

38. Dong YW, Shi YQ, He LW, et al. Effects of metformin on survival outcomes of pancreatic cancer: a meta-analysis. Oncotarget. 2017; 8(33): 55478-55488, doi: 10.18632/oncotarget.18233, indexed in Pubmed: 28903435

39. Wei M, Liu Yu, Bi Y, et al. Metformin and pancreatic cancer survival: Real effect or immortal time bias? Int J Cancer. 2019; 145(7): 1822-1828, doi: 10.1002/ijc.32254, indexed in Pubmed: 30848544.

40. Dankner R, Roth J. More recent, better designed studies have weakened links between antidiabetes medications and cancer risk. Diabet Med. 2020; 37(2): 194-202, doi: 10.1111/dme.14179, indexed in Pubmed: 31769894.

41. Drzewoski J, Hanefeld M. The Current and Potential Therapeutic Use of Metformin-The Good Old Drug. Pharmaceuticals (Basel). 2021; 14(2), doi: 10.3390/ph14020122, indexed in Pubmed: 33562458.

42. Peric S, Stulnig TM. Diabetes and COVID-19 : Disease-Management-People. Wien Klin Wochenschr. 2020; 132(13-14): 356-361, doi: 10.1007/s00508-020-01672-3, indexed in Pubmed: 32435867.

43. Scheen AJ. Pharmacodynamics, efficacy and safety of sodium-glucose co-transporter type 2 (SGLT2) inhibitors for the treatment of type 2 diabetes mellitus. Drugs. 2015; 75(1): 33-59, doi: 10.1007/s40265-014-0337-y, indexed in Pubmed: 25488697.

44. Moses RG, Colagiuri S, Pollock C. SGLT2 inhibitors: New medicines for addressing unmet needs in type 2 diabetes. Australas Med J. 2014; 7(10): 405-415, doi: 10.4066/AMJ.2014.2181, indexed in Pubmed: 25379062.

45. Tang H, Yang K, Li X, et al. Pancreatic safety of sodium-glucose cotransporter 2 inhibitors in patients with type 2 diabetes mellitus: A systematic review and meta-analysis. Pharmacoepidemiol Drug Saf. 2020; 29(2): 161-172, doi: 10.1002/pds.4943, indexed in Pubmed: 32017292.

46. Holst JJ. The incretin system in healthy humans: The role of GIP and GLP-1. Metabolism. 2019; 96: 46-55, doi: 10.1016/j.metabol.2019.04.014 indexed in Pubmed: 31029770.

47. Gallwitz B. Clinical Use of DPP-4 Inhibitors. Front Endocrinol (Lausanne). 2019; 10: 389, doi: 10.3389/fendo.2019.00389, indexed in Pubmed: 31275246. 
48. Zhang Z, Chen Xi, Lu P, et al. Incretin-based agents in type 2 diabetic patients at cardiovascular risk: compare the effect of GLP-1 agonists and DPP-4 inhibitors on cardiovascular and pancreatic outcomes. Cardiovasc Diabetol. 2017; 16(1): 31, doi: 10.1186/s12933-017-0512-z, indexed in Pubmed: 28249585.

49. Abd El Aziz M, Cahyadi O, Meier JJ, et al. Incretin-based glucose-lowering medications and the risk of acute pancreatitis and malignancies: a meta-analysis based on cardiovascular outcomes trials. Diabetes Obes Metab. 2020; 22(4): 699-704, doi: 10.1111/dom.13924, indexed in Pubmed: 31750601.

50. Dicembrini I, Montereggi C, Nreu B, et al. Pancreatitis and pancreatic cancer in patientes treated with Dipeptidyl Peptidase- 4 inhibitors: An extensive and updated meta-analysis of randomized controlled trials. Diabetes Res Clin Pract. 2020; 159: 107981, doi: 10.1016/j.diabres.2019.107981, indexed in Pubmed: 31870827.

51. Almagthali AG, Alkhaldi EH, Alzahrani AS, et al. Dipeptidyl peptidase- 4 inhibitors: Anti-diabetic drugs with potential effects on cancer. Diabete Metab Syndr. 2019; 13(1): 36-39, doi: 10.1016/j.dsx.2018.08.012, indexed in Pubmed: 30641726.

52. Abdelmoneim AS, Hasenbank SE, Seubert JM, et al. Variations in tissue selectivity amongst insulin secretagogues: a systematic review. Diabetes Obes Metab. 2012; 14(2): 130-138, doi: 10.1111/j.1463-1326.2011.01496.x indexed in Pubmed: 21923736.

53. Khunti K, Chatterjee S, Gerstein H, et al. Do sulphonylureas still have a place in clinical practice? Lancet Diabetes Endocrinol. 2018; 6(10): 821-832, doi: 10.1016/s2213-8587(18)30025-1, indexed in Pubmed: 29501322.

54. Stefansdottir G, Zoungas S, Chalmers J, et al. Intensive glucose control and risk of cancer in patients with type 2 diabetes. Diabetologia. 2011; 54(7): 1608-1614, doi: 10.1007/s00125-011-2104-x, indexed in Pubmed: 2150944.

55. Calip GS, Yu O, Elmore JG, et al Comparative safety of diabetes medications and risk of incident invasive breast cancer: a population-based cohort study. Cancer Causes Control. 2016; 27(5): 709-720, doi: 10.1007/s10552-016-0744-3, indexed in Pubmed: 27053250.

56. Häggström C, Van Hemelrijck M, Zethelius B, et al. Prospective study of Type 2 diabetes mellitus, anti-diabetic drugs and risk of prostate cancer. Int J Cancer. 2017; 140(3): 611-617, doi: 10.1002/ijc.30480, indexed in Pubmed: 27770555.

57. Ye JH, Qian MH, Shi LZ, et al. Association Between Metformin and Sulfonylurea Monotherapies and Cancer Incidence: A Real-World Cohort Study in Shanghai, China. Diabetes Ther. 2019; 10(1): 245-258, doi: 10.1007/s13300-018-0557-3, indexed in Pubmed: 30623338.

58. Chaudhury A, Duvoor C, Reddy Dendi VS, et al Clinical Review of Antidiabetic Drugs: Implications for Type 2 Diabetes Mellitus Management. Front Endocrinol (Lausanne). 2017; 8: 6, doi: 10.3389/fendo.2017.00006, indexed in Pubmed: 28167928.

59. Li D, Yeung SCJ, Hassan MM, et al. Antidiabetic therapies affect risk of pancreatic cancer. Gastroenterology. 2009; 137(2): 482-488, doi: 10.1053/j. gastro.2009.04.013, indexed in Pubmed: 19375425.

60. Nanjan MI, Mohammed M, Prashantha Kumar BR et al. Thiazolidinediones as antidiabetic agents: A critical review. Bioorg Chem. 2018; 77: 548-567, doi: 10.1016/j.bioorg.2018.02.009, indexed in Pubmed 29475164.

61. Lebovitz HE. Thiazolidinediones: the Forgotten Diabetes Medications. Curr Diab Rep. 2019; 19(12): 151, doi: 10.1007/s11892-019-1270-y, indexed in Pubmed: 31776781.

62. Della-Morte D, Palmirotta R, Rehni AK, et al. Pharmacogenomics and pharmacogenetics of thiazolidinediones: role in diabetes and cardiovascular risk factors. Pharmacogenomics. 2014; 15(16): 2063-2082, doi: 10.2217/pgs.14.162, indexed in Pubmed: 25521362

63. Lewis JD, Habel LA, Quesenberry CP, et al. Pioglitazone Use and Risk of Bladder Cancer and Other Common Cancers in Persons With Diabetes. JAMA. 2015; 314(3): 265-277, doi: 10.1001/jama.2015.7996, indexed in Pubmed: 26197187.

64. Hedrington MS, Davis SN. Considerations when using alpha-glucosidase inhibitors in the treatment of type 2 diabetes. Expert Opin Pharmacother. 2019; 20(18): 2229-2235, doi: 10.1080/14656566.2019.167 2660, indexed in Pubmed: 31593486.

65. Zhao $\mathrm{Y}$, Wang $\mathrm{Y}$, Lou $\mathrm{H}$, et al. Alpha-glucosidase inhibitors and risk of cancer in patients with diabetes mellitus: a systematic review and meta-analysis. Oncotarget. 2017; 8(46): 81027-81039, doi: 10.18632/oncotarget.17515, indexed in Pubmed: 29113364 